\title{
In-situ strength estimation of polypropylene fibre reinforced recycled aggregate concrete using Schmidt rebound hammer and point load test
}

Kazemi, Mostafa; Hajforoush, Mohammad; Talebi, Pouyan Khakpour; Daneshfar, Mohammad; Shokrgozar, Ali; Jahandari, Soheil; Saberian Boroujeni, Mohammad

https://researchrepository.rmit.edu.au/esploro/outputs/9921970151501341/filesAndLinks?institution=61RMIT_INST\&index=null

Kazemi, M., Hajforoush, M., Talebi, P. K., Daneshfar, M., Shokrgozar, A., Jahandari, S., Saberian Boroujeni, M., \& Li, J. (2020). In-situ strength estimation of polypropylene fibre reinforced recycled aggregate concrete using Schmidt rebound hammer and point load test. Journal of Sustainable Cement-Based Materials, 9(5), 289-306. https://doi.org/10.1080/21650373.2020.1734983

Document Version: Accepted Manuscript

Published Version: https://doi.org/10.1080/21650373.2020.1734983

Repository homepage: https://researchrepository.rmit.edu.au CC BY-NC-ND V4.0

(c) 2020 Informa UK Limited, trading as Taylor \& Francis Group

Downloaded On 2023/04/26 22:28:51 +1000 


\title{
In-situ strength estimation of polypropylene fibre reinforced recycled aggregate concrete using Schmidt rebound hammer and point load test
}

\author{
Mostafa Kazemi $^{1}$ *, Mohammad Hajforoush ${ }^{2}$, Pouyan Khakpour Talebi ${ }^{3}$, Mohammad \\ Daneshfar $^{4}$, Ali Shokrgozar ${ }^{5}$, Soheil Jahandari ${ }^{6}$, Mohammad Saberian ${ }^{7}, \mathrm{Jie}^{\mathbf{L i}^{8}}$
}

Corresponding author *

${ }^{1}$ Ph.D. Candidate, GeMMe Sector, ArGEnCo Department, Urban and Environmental Engineering, University of Liège, Liège, Belgium, E-mail: kazemi.civil68@gmail.com, mostafa.kazemi@uliege.be

${ }^{2}$ Ph.D. Candidate, Department of Civil Engineering, Semnan University, Semnan, Iran, Email: mhajforoush@semnan.ac.ir

${ }^{3}$ MSc Graduate Student, Department of Civil Engineering, Islamic Azad University, Bushehr Branch, Iran, pouyan.khakpour@gmail.com

${ }^{4}$ MSc Graduate Student, Department of Civil Engineering, Deylaman Institute of Higher Education, Lahijan, Guilan, Iran, moh4mmad.daneshfar@gmail.com

${ }^{5} \mathrm{Ph} . \mathrm{D}$. Candidate, Department of Civil and Environmental Engineering, Idaho State University, Idaho, USA, E-mail: $\underline{\text { shokali@isu.edu }}$

${ }^{6} \mathrm{Ph} . \mathrm{D}$. Candidate, Center for Infrastructure Engineering, Western Sydney University, Sydney, Australia, E-mail: 19625599@student.westernsydney.edu.au

${ }^{7}$ Ph.D. Candidate, School of Engineering, RMIT University, Melbourne, Victoria, Australia, Eamil: s3609245@ student.rmit.edu.au

${ }^{8}$ Professor, School of Engineering, RMIT University, Victoria, Australia, E-email: jie.li@rmit.edu.au 


\title{
In-situ strength estimation of polypropylene fibre reinforced recycled aggregate concrete using Schmidt rebound hammer and point load test
}

\author{
Mostafa Kazemi $^{1}$ *, Mohammad Hajforoush ${ }^{2}$, Pouyan Khakpour Talebi ${ }^{3}$, Mohammad \\ Daneshfar $^{4}$, Ali Shokrgozar ${ }^{5}$, Soheil Jahandari ${ }^{6}$, Mohammad Saberian ${ }^{7}$, Jie Li $^{8}$
}

\begin{abstract}
An appropriate amount of polypropylene fibre (PF) content is generally able to compensate for the low compressive strength of the recycled aggregate concrete. This mechanical strength is required to reliably estimate at the building site using partially and non-destructive testing methods. Therefore, in the present study, the compressive strength of concrete with PF at $0.1 \%$ by volume and different replacement levels of recycled coarse aggregate (RCA) was assessed using point load test (PLT) and Schmidt rebound hammer. According to the results, the sensitivity of the core specimens to the concentrated point load and the short size of PF in the failure zone of the PLT caused to appear a difference among the enhancement trends of PLI values by increasing the age. In addition, a two-variable equation between the rebound number and point load index (PLI) reliably predicted either strength of coarse natural concrete or recycled aggregate concrete or PRAC.
\end{abstract}

Keywords: In-situ strength estimation; Recycled coarse aggregate; Polypropylene fibres; Point load test; Schmidt rebound hammer.

\section{Introduction}

Over the last decade, the estimation of the in-situ strength of specific types of concrete materials such as recycled aggregate concrete has drawn much attention from researchers owing to the difference between the manufacturing conditions of existing concrete at the construction sites and those of standard samples in the laboratory. Therefore, partially and nondestructive testing methods have been proposed to estimate the on-site strength of concrete materials [1-6]. The point load test (PLT), as one of the partially destructive testing methods, 
includes two concentrated point loads applied to the lateral surface of the core specimen. Due to the cheapness and portability of PLT's apparatus, it can be easily utilized to estimate the onsite strength of the core specimen without the need to be trimmed and capped after extracting from concrete elements [7-9]. For the strength estimation of concrete materials, PLT was first used by Robins [8], and then other researchers employed it at the building sites. Following this, Ishibashi et al. [10] demonstrated that the results of drilled core specimens with the L/D ratio of 2 were more reliable than those with other L/D ratios. Recently Madandoust et al. [9] demonstrated that the strength of coarse natural concrete could be realistically estimated using the correlation curves between PLT and the compression test. Furthermore, the in-situ strength estimation of concrete mixes by the PLT under wet curing regime was averagely obtained $12 \%$ more than that under dry curing regime. Although this applicable non-destructive testing method has been extensively used for the strength estimation of conventional concrete, there is few research focusing on specific types of composite materials including fibre reinforced recycled aggregate concrete using the PLT.

Another non-destructive testing method is the Schmidt rebound hammer test, which has been widely used in practice owing to its cheapness, smallness and portability [7, 11]. The rebound number as a scale index in the Schmidt hammer test can be employed for the strength estimation of concrete materials in precast works and the building site by the generation of correlation curves between the aforementioned number and the cube compressive strength [12]. The results given by Grieb [13] showed that the rebound number of concrete materials with a specific type of aggregate was different to that with the same type of aggregate, provided from another source, while the difference between the data of Schmidt hammer test at various locations of a concrete element was negligible as reported by $\mathrm{Xu}$ and Li [14]. In 2019, Kazemi et al. [3] combined the results of Schmidt rebound hammer with the core testing method to estimate the compressive strength of a limited number of concrete samples made by the partial replacement of natural aggregates with recycled coarse aggregate (RCA). As per the results, there was a strong correlation between Schmidt rebound hammer and the core testing method to reliably estimate the in-situ strength of concrete. They also demonstrated that the difference between the data of Schmidt rebound hammer and compression tests was found to be $10 \%$ at the most. Generally, it can be stated that the Schmidt rebound hammer as a reliably applicable testing method can be easily combined with other non-destructive testing methods to predict the in-situ strength of concrete materials.

The building industries extract about 7.5 billion tonnes of natural aggregates annually from the 
earth, which has significant adverse effects on the environment. The overexploitation of natural resources and environmental degradation can be unravelled by the substitution of natural aggregates with RCA in civil and construction engineering [15-23]. On the other hand, the mechanical properties of recycled aggregate concrete are lower than those of the normal aggregate concrete due to the weaker bonds of adhered old mortar to RCA with cement particles, leading to decreasing the compressive strength of recycled aggregate concrete as reported by Assaad et al. [24]. The low mechanical strength of RCA can be somewhat compensated by means of appropriate contents of additives such as polypropylene fibre (PF) in concrete materials [25-26]. For example, Matar and Assaad [27] showed that the simultaneous use of RCA and PF additions caused an increase in the segregation resistance of concrete mixtures. This was attributed to the coupled effect of the continuous network of inter-particles links in fibrous concrete together with greater relative water absorption of RCA that reduces the detrimental effects of free mixing water in fresh concrete. So, PF with a high strain-hardening response can be utilized to enhance the mechanical strength of recycled aggregate concrete. Regarding the appropriate amount of PF, in 2018, Das et al. [28] performed a microscopic study on recycled aggregate concrete containing PF at $0.5-1 \%$ by volume. According to the results, the old mortar, adhered to RCA, had higher air content, leading to decreasing the compressive strength of recycled aggregate concrete. In addition, the PF content somewhat bridged the micro-cracks. However, based on the microstructure analysis of concrete, the use of higher fibres volume caused to generate more voids between the PF and cement paste. Therefore, $\mathrm{PF}$ at $0.5-1 \%$ by volume decreased the compressive strength of recycled aggregate concrete. In 2019, another study by Madandoust et al. [29] demonstrated only $0.1 \%$ PF slightly improved the compressive strength of lightweight concrete. Similar results were also obtained by Fallah and Nematzadeh [30]. They demonstrated that the generation of the cohesion and bond between aggregates and cement particles due to the presence of PF in concrete mixes led to decreasing the slump value.

Due to the difference between the compaction and curing conditions of existing concrete at the building site and those of standard samples in the laboratory [7], it is required to combine partially and non-destructive testing methods to reliably estimate the in-situ strength of concrete materials at the construction location without the need for the results of compression test in the laboratory. On the other hand, few studies have been conducted to predict the in-situ strength of specific types of concrete materials such as polypropylene fibre reinforced recycled aggregate concrete (PRAC) particularly by means of PLT and Schmidt rebound hammer. Therefore, by considering the fact that these two easily utilized methods are known 
for the cheapness and portability of their apparatus [7], and there is an urgent need for predicting the in-situ strength of PRAC using partially and non-destructive testing methods. In this study, simple one-variable equations were developed by means of PLT and Schmidt rebound hammer to reliably determine the in-situ strength of polypropylene fibre reinforced concrete mixes prepared with $50 \%$ and $100 \%$ replacements of coarse natural aggregate with RCA. In addition, since the mechanical strength of concrete materials can be influenced by the curing regimes [31-32], all mixes were cured under both wet and dry curing regimes and the combination of the methods were utilized to obtain a reliable two-variable equation between the PLI and rebound number to reliably predict the in-situ strength of PRAC at early and old ages under different curing conditions.

\section{Experimental program}

\subsection{Materials}

Type II Portland cement with moderate sulfate resistance property was used in this study. This type of cement has a density of $3155 \mathrm{~kg} / \mathrm{m}^{3}$ and the surface area of $3200 \mathrm{~cm}^{2} / \mathrm{g}$. Table 1 shows its chemical compositions. The density, water absorption, Los Angeles abrasion, and the maximum size of gravel were $2700 \mathrm{~kg} / \mathrm{m}^{3}, 1.4 \%, 26.7 \%$, and $19 \mathrm{~mm}$, respectively. The corresponding values for RCA (Fig. 1(a)) were found to be $2400 \mathrm{~kg} / \mathrm{m}^{3} 4.8 \%, 32.6 \%$, and 19 $\mathrm{mm}$, respectively. The old mortar, adhered to RCA, mostly contained fine aggregate, hydrated, and unhydrated cement particles. Meanwhile, the density, water absorption and the size range of sand were $2700 \mathrm{~kg} / \mathrm{m}^{3}, 0.43 \%$, and $0-4.75 \mathrm{~mm}$, respectively. An appropriate superplasticizer, namely polycarboxylic ether-type was added to the mixes to attain the intended concrete workability suggested by other researchers [33, 34]. In addition, PF with the white colour was added to the mixes, as shown in Fig. 1(b). The length, diameter, bulk

density, and tensile strength of PF content were equal to $12 \mathrm{~mm}, 18 \mu \mathrm{m}, 0.91 \mathrm{gr} / \mathrm{cm}^{3}$, and 400 $\mathrm{MPa}$, respectively. Fig. 2 shows the size grading curves of the aggregates and cement particles.

\subsection{Mix proportioning and sample preparation}

Table 2 shows the total number of 12 concrete mix designs made in this study. PF at $0.1 \%$ by 
volume was added to 8 concrete mix designs. To make concrete mixes, the effective water/binder (W/B) ratios of 0.4 and 0.55 were used to assess the effects of high and low W/B ratios on the results of this study. A study by Ferreira et al. [35] showed that the slump values for concrete with different substitutions of coarse natural aggregate with RCA were in the range of 70 to 90 $\mathrm{mm}$. To achieve this range, concrete mix designs with a low W/B ratio (0.4) were made using superplasticizer to achieve appropriate workability for all mixes [28]. The experimental evaluations showed that the superplasticizer with a dosage of $0.8 \mathrm{~kg} / \mathrm{m}^{3}$ could be considered as an optimum value to attain the range given by Ferreira et al. [35]. The saturated surface-dry condition was introduced in all aggregates to avoid absorbing the free water, particularly by RCA. Concerning the optimum amount of PF content, Madandoust et al. [29] showed that the highest amount of compressive strength was obtained for the concrete with $0.1 \% \mathrm{PF}$. Therefore, concrete mixes were made with $0.1 \%$ PF in this study.

For mix preparation, all fine and coarse aggregates were first blended for at least 30 seconds. Mixing continued for one more minute by introducing half of the water to the mixer. Cement was then added to the blended aggregates with tap water, and the mixer revolved for one more minute. To avoid clustering of the PF, this incorporation was intermittently introduced to the mixer, along with the remaining water and superplasticizer, and mixing went on for three more minutes. Finally, $10 \mathrm{~cm}$ cubes samples and concrete slabs were made and cast.

The molds were covered with a wet sack and cured at $22-24{ }^{\circ} \mathrm{C}$ for 24 hours. Later on, after removed from molds, the samples were kept under the lab condition (dry curing regime) until the time of testing. Under the wet curing regime, the demolded concrete samples were immersed in a water tank at $24^{\circ} \mathrm{C}$ until the date of testing (i.e., 5, 7, 28, and 56 days).

For each age and curing condition, three cubic specimens were used to obtain the results of cube testing. These specimens were exposed to the Schmidt rebound hammer test before putting in the compression testing machine. In the Schmidt rebound hammer test, the plunger was pressed forcefully and steadily against the cube specimen at right angles to its smooth surface, according to the BS 1881: Part 202 [36] and ASTM C805 [37]. Thereafter, the rebound number was recorded, while the hammer was still in the test position. In the PLT method, as recommended by Bungey et al. [7], the cylindrical specimen was broken, while it was exposed to an increasingly concentrated point load, applied through a pair of conical platens. In this test, the average number of three cylindrical specimens was drilled and extracted from slab samples at each age and curing condition. Therefore, the PLI values were the average of three cylindrical specimens. Furthermore, the diameter and the length to 
diameter (L/D) ratio of core specimens were considered $70 \mathrm{~mm}$ and 2, respectively, as suggested by Ishibashi et al. [10]. It is noteworthy that the presence of steel bars in concrete slabs could affect the results of the PLT method, while the objective of this study was to assess the effect of PF content on the in-situ strength of recycled aggregate concrete. Therefore, the slab samples were considered to be unreinforced.

\section{Results and discussion}

\subsection{Slump}

In this study, the slump values of concrete mixes were in the range of 66 to $75 \mathrm{~mm}$, as presented in Table 3. This range was found to be between 70 to $90 \mathrm{~mm}$ for concrete with different substitutions of coarse natural aggregate with RCA as given by Ferreira et al. [35]. To obtain appropriate workability for all mixes, the superplasticizer was added to the concrete mixes with a low W/B ratio (0.4). That is why the slump values of concrete mixes with W/B ratio of 0.4 were nearly the same as those concrete mixes with W/B ratio of 0.55 . The high porosity of RCA, as well as high cohesion between PF and concrete matrix [28], led to decreasing slump values by increasing the amount of RCA and PF.

\subsection{Cube compressive strength}

Figs. 3 and 4 show the cube compressive strength of the fibre reinforced concrete mixes with $50 \%$ and $100 \%$ substitutions of coarse natural aggregates with RCA. The ranges of 16.1-41.6 $\mathrm{MPa}$ and 13.9-38.1 $\mathrm{MPa}$ were for mixes with $\mathrm{W} / \mathrm{B}$ ratio of 0.4 under wet and dry curing regimes, respectively (Fig. 3). Fig. 4 shows that the corresponding ranges for those mixes with W/B ratio of 0.55 under wet and dry curing regimes were 12.5-33.8 $\mathrm{MPa}$ and 10.7-28.9 $\mathrm{MPa}$, respectively.

For W/B ratio of 0.4 , the maximum and minimum strengths were obtained for NCPF-L and $\mathrm{RC} 100-\mathrm{H}$, respectively, under different curing regimes, as shown in Figs. 3 and 4. Therefore, it can be stated that PF content generated a suitable cohesion within the concrete matrix and slightly improved the cube compressive strength, similarly to what Fallah and

Nematzadeh [30] reported, while the substitution of natural aggregate with RCA led to decreasing the results of RC100-L and $\mathrm{RC} 100-\mathrm{H}$ due to lower mechanical strength of RCA than coarse natural aggregate $[2,3]$. Furthermore, the low mechanical strength of concrete 
mixes was slightly enhanced by decreasing the replacement level of coarse natural aggregate with RCA from $100 \%$ to $50 \%$ (RC50-L and RC50-H). This improvement was also observed by adding PF to concrete mixes with 100\% substitution of RCA (RC100-L and RC100PF-H).

The average amount of 28-day cube compressive strength was $66.8 \%$ more than that at 5 and 7 days. The corresponding value at 56 days was averagely obtained $20.2 \%$ more than that at 28 days. Therefore, it can be stated that in most cases, there was a remarkable enhancement of compressive strength for concrete mixes from early ages (5 and 7 days) to middle age (28 days), while a slight enhancement appeared in most cases from the middle age (28 days) to old age (56 days).

The results showed that the SD values of the mixes with W/B ratio of 0.4 were found to be nearly the same as those with W/B ratio of 0.55 . This can be owing to the fact that the superplasticizer was only added to concrete mixes with low W/B ratio $(0.4)$ to improve the workability of concrete mixes, which led to the dissipation of cement particles from each other [38], and subsequently caused the cube compressive strengths to be scattered more. That is why the difference between the dissipation of the data of mixes with W/B ratios of 0.4 and 0.55 was negligible.

The average value SD was obtained $59.8 \%$ more for mixes under dry curing regime than those under wet curing regime. The PF content can generate the air-voids in the blends, as reported by Madandoust et al. [28]. By considering this, the SD values of concrete specimens made with PF were averagely obtained $25.2 \%$ more than those with no PF. The results showed that the SD values increased up to $46.8 \%$ and $89.4 \%$ by $50 \%$ and $100 \%$ replacements of coarse natural aggregate with RCA, respectively, which can be owing to low mechanical strength and quality of RCA compared to coarse natural aggregates.

\subsection{PLT}

The results of PLT on core specimens made with PF as well as 50\% and $100 \%$ substitutions of coarse natural aggregates with RCA are depicted in Figs. 5 and 6. As shown in Fig. 5, the ranges of 2.2-3.4 $\mathrm{MPa}$ and 1.9-2.9 $\mathrm{MPa}$ were obtained for PLI values of mixes with W/B ratio of 0.4 under wet and dry curing regimes, respectively. The corresponding ranges for those mixes with W/B ratio of 0.55 under wet and dry curing conditions were obtained 1.62.4 MPa and 1.3-2.1 MPa, respectively (Fig. 6). The 28-day PLI value of concrete mixes with W/B ratio of $0.55(\mathrm{NC}-\mathrm{H})$ under wet curing condition was obtained at $2.02 \mathrm{MPa}$. The corresponding value was obtained at 2.3 MPa as given by Madandoust et al. [9]. This moderate 
difference can be due to the sensitivity of the core specimens to the concentrated point load. According to the results, the average value of PLI was $42.4 \%$ more fore mixes with W/B ratio of 0.4 than those with W/B ratio of 0.55 . Furthermore, the average value of PLI was $17.7 \%$ more for mixes under wet curing regime than those under dry curing regime. The corresponding value given by Madandoust et al. [9] for normal concrete specimens was $12 \%$.

The maximum and minimum cube compressive strengths were obtained for NCPF-L and RC100-H, respectively, similarly to the compression test (Figs. 5 and 6). PLI values of concrete mixes with PF content increased up to $18.1 \%$ due to the generation of suitable bond quality between cement particles and aggregates by the inclusion of PF [28].

Contrarily to the compression test, there was a difference among the enhancement trends of PLI values by increasing the age. For instance, the slope of PLI enhancement for RC50PF$\mathrm{L}$ with W/B ratio of 0.4 at old age was higher than that at an early age, while the contrary occurred for NC-L (Fig. 5 (b)). This can be due to the sensitivity of core specimens to the concentrated point load and the short size of PF in the failure zone of the PLT as shown in Fig. 7.

The 28-day SD values of the control concrete specimens with W/B ratios of 0.4 (NC-L) and $0.55(\mathrm{NC}-\mathrm{H})$ under wet curing regime were $0.09 \mathrm{MPa}$ and $0.1 \mathrm{MPa}$, respectively. The corresponding values given by Madandoust et al. [9] were in the range of 0.08-0.13 MPa. The average value SD was obtained $33.8 \%$ lower for mixes under wet curing regime than those under dry curing regime. The SD values of concrete mixes with PF content were averagely obtained $30.1 \%$ more than those with no PF content. The corresponding value in the compression test was obtained at $25.2 \%$. Therefore, the use of PF in the concrete mixes caused to slightly dissipate the data more in the PLT than in the compression test. PF content slightly dissipated the data in the PLT more than that in the compression test. There are two explanations for this difference. First, there was a limited contact surface between the core specimen and load cell in the PLT, where the load was applied to the concrete specimen only via two concentrated point loads as shown in Fig. 7. Second, the length of PF is short and, in some cases, it cannot effectively bridge the micro-cracks in the failure zone of core specimens in the PLT (Fig. 7), leading to more dissipation of the data. A similar study on the microstructure analysis of PRAC by Acka et al. [39] showed that by increasing the substitution level of coarse natural aggregate with RCA, the void content increased and debonding was observed on PF. This made the core specimens sensitive to air-voids generated by $\mathrm{PF}$ in the failure zone and subsequently scattered data more in the PLT. According to the results, there was an increase in SD values up to $18.2 \%$ and $34.1 \%$ by $50 \%$ 
and $100 \%$ replacements of coarse natural aggregate with RCA, respectively.

\subsubsection{Variation of cube compressive strength and PLI}

Strength correlations between PLI and cube compressive strength are shown in Fig. 8 and their one variable equations for low and high W/B ratios are presented in Table 4 . The values of coefficient of determination $\left(\mathrm{R}^{2}\right)$ were obtained greater than 0.72 (see Table 4), indicating a strong correlation between the PLI and cube compressive strength. The slopes of different correlation curves were found to be nearly similar to each other. However, there was a remarkable difference between the correlation curves of mixes made with W/B ratios of 0.4 and 0.55 (Fig. 8). Therefore, it can be stated that strength correlations were effectively dependent on the W/B ratio of concrete mixes to achieve reliable equations between the PLI and cube compressive strength. This difference showed that the amount of water remarkably affected the cohesion and bond quality between PF and the concrete matrix, particularly in the failure zone of the PLT (Fig. 7) owing to the short and small size of PF.

\subsection{Schmidt rebound hammer test}

The results of the Schmidt rebound hammer test on core specimens made with PF and 50\% and $100 \%$ substitutions of coarse natural aggregates with RCA are shown in Figs. 9 and 10. As shown in Fig. 9, the ranges of 12.5-34.2 and 11.1-28.2 were obtained for mixes with W/B ratio of 0.4 under wet and dry curing regimes, respectively. According to Fig. 10, the corresponding ranges for those mixes with W/B ratio of 0.55 under wet and dry curing conditions were obtained 9.3-25.9 and 8.5-21.2, respectively (Fig. 10). For the W/B ratio of 0.4 , the 28-day rebound numbers of concrete mixes with no RCA (NC-L) and with 50\% incorporation of RCA (RC50-L) under wet curing conditions were obtained at 26.4 and 23.9, respectively. The corresponding values given by Kazemi et al. [3] for concrete mixes with no RCA and with 70\% incorporation of RCA were equal to 25 and 22, respectively. So, the results of this study were found to be nearly the same as those reported by Kazemi et al. [3]. The average amount of rebound numbers was obtained $32.3 \%$ more for mixes with W/B ratio of 0.4 than those with W/B ratio of 0.55 . Furthermore, the rebound number of mixes under wet curing regime was averagely obtained $14.4 \%$ more than that under wet curing regime.

The average rebound numbers of concrete mixes with $50 \%$ and $100 \%$ replacements of coarse natural aggregate with RCA were $11.3 \%$ and $19.5 \%$ lower than those of the control 
mix. It can be stated that old mortar adhered to RCA as well as micro-cracks and porosity generated in this aggregate led to decreasing the quality and mechanical strength of recycled coarse aggregate [40] as shown in Fig. 11. Regarding this, another study at the microscopic scale by Das et al. [28] revealed that the old mortar, adhered to RCA, had higher air content, leading to decreasing the compressive strength of recycled aggregate concrete. PF resulted in increasing the rebound number of concrete mixes up to $3.5 \%$. Therefore, the addition of PF at $0.1 \%$ by volume slightly enhanced the mechanical strength of mixes, similarly to what was obtained in the compression test.

In the Schmidt rebound hammer test, for the W/B ratio of 0.4, the SD values of mixes with $50 \%$ substitution of coarse natural aggregate with RCA under different curing conditions at 28 days were in the range of 1.2-1.4. The corresponding values given by Kazemi et al. [3] for mixes with 70\% substitution of coarse natural aggregate with RCA were in the 1.4-1.6 range. The SD values under dry curing regime were averagely about $18.9 \%$ more than those under wet curing regime. Meanwhile, the SD values of mixes made with PF were averagely obtained $23.2 \%$ more than those with no PF, which can be attributed to the generated airvoids in mixes by the inclusion of PF as reported by Madandoust et al. [29]. The SD values of concrete mixes increased up to $44.4 \%$ and $85.5 \%$ by $50 \%$ and $100 \%$ replacements of coarse natural aggregate with RCA, respectively. Therefore, the low quality of RCA owing to the adhered old mortar and generated micro-cracks and porosity in the surface of this aggregate (Fig. 11) led to more dissipation of rebound numbers.

\subsubsection{Variation of cube compressive strength and rebound number}

Strength correlations between the rebound number and cube compressive strength are shown in Fig. 12 and their one variable equations for low and high W/B ratios are presented in

Table 4 . The values of coefficient of determination $\left(\mathrm{R}^{2}\right)$ were obtained greater than 0.97 (see Table 4). As depicted in Fig. 12, similar trends were obtained for different correlation curves between the rebound number and cube compressive strength. In addition, the correlation curves of mixes made with W/B ratio of 0.4 were found to be near to those with W/B ratio of 0.55 , contrarily to what occurred for the correlation curves of PLI and cube compressive strength (Fig. 8).

\subsection{Strength estimation by PLI values and rebound numbers}


To draw a reliable two-variable equation for the strength estimation of mixes, the combination of rebound numbers and PLI values was used. The total number of data was equal to 96 for each test. Among these, 84 data were randomly chosen and then they were introduced to the SPSS software to draw the two-variable equation. Later on, the remaining data (12 data) were used to assess the reliability of the aforementioned equation as shown in Table 3. The proposed equation with the coefficient of determination $\left(R^{2}\right)$ of 0.98 is presented in Eq. 1, where the $\mathrm{RN}$ is the rebound number.

$$
\mathrm{f}_{\mathrm{c}}=-0.414 \text { PLI + 1.304 RN +1.678 } \quad\left(\mathrm{R}^{2}=0.98\right)
$$

The cube compressive strength of concrete mixes estimated by one-variable equations of PLT and Schmidt rebound hammer were compared to that of the two-variable equation, and the percentages in parentheses, presented in Table 3, express the differences between them. The one-variable equations were obtained using correlation curves shown in Figs. 8 and 12. The maximum difference of $7.9 \%$ was observed between the rebound number and the measured compressive strength (Table 3). The corresponding difference given by Kazemi et al. [3] only for the recycled aggregate concrete was $10 \%$. As seen in Table 3, the highest difference between the data of the compression test present and PLT was 38.1\%. However, the highest difference of $7.4 \%$ was observed between the data of the compression test and that obtained by the two-variable equation. So, the estimated cube strengths by the twovariable equation were more reliable than those by one-variable equations. Generally, it was required to separately obtain one-variable equations for each mixture using the correlation curves shown in Figs. 8 and 12 to determine the compressive strength of concrete, while the two-variable equation can be used for all mixes including coarse natural concrete, recycled aggregate concrete and PRAC under wet and dry curing regimes at early and old ages. Therefore, the reliability of two-variable equation between PLI and rebound number was found to be more than that of one-variable equations to reliably determine the in-situ strength of the mixes at the building site.

\section{Conclusion}

The present study proposed a method for estimating the in-situ strength of coarse natural concrete, recycled aggregate concrete and PRAC using PLT, Schmidt rebound hammer, and 
the combination of two test methods. According to the laboratory study, the following conclusions can be drawn:

- The average strength of mixes cured under wet curing condition was obtained to be $13.8 \%$ more than that cured under dry curing condition. The corresponding value was $28.4 \%$ more for mixes with $\mathrm{W} / \mathrm{B}$ ratio of 0.4 than mixes with W/B ratio of 0.55 .

- For W/B ratio of 0.4 , the highest and lowest values of cube compressive strength were obtained for NCPF-L and RC100-L, respectively. For W/B ratio of 0.55 , NCPF-H and RC100-H obtained the highest and lowest cube compressive strength, respectively, similarly to what occurred in the PLT and Schmidt rebound hammer test.

- Similarly to the Schmidt rebound hammer test, in most cases, there was a remarkable enhancement of cube compressive strength for concrete mixes from early ages ( 5 and 7 days) to middle age ( 28 days), while a moderate enhancement appeared in most cases from the middle age (28 days) to older age (56 days). However, the sensitivity of the core specimens to the concentrated point load and the short size of PF in the failure zone of the PLT caused to appear a difference among the enhancement trends of PLI values by increasing the age.

- In the compression test, the use of superplasticizer in mixes with W/B ratio of 0.4 increased the SD values. Therefore, the SD values of mixes with W/B ratio of 0.4 were found to be nearly the same as those with W/B ratio of 0.55 . Meanwhile, the results dissipated 59.8\% more under dry curing regime than under wet curing regime. In addition, the SD values increased up to $46.8 \%$ and $89.4 \%$ by $50 \%$ and $100 \%$ replacements of coarse natural aggregate with RCA, respectively.

- In the PLT, the inclusion of PF led to the dissipation of PLI values $30.1 \%$ more. The corresponding value in the compression test was obtained at $25.2 \%$. Therefore, the use of PF in the concrete mixes caused to slightly dissipate the data more in the PLT than in the compression test. PF content increased the rebound number of concrete mixes up to $3.5 \%$. Therefore, this content slightly improved the mechanical strength of concrete mixes, similarly to what was obtained in the compression test.

- The amount of water remarkably affected the cohesion and bond quality between PF and the concrete matrix, particularly in the failure zone of the PLT. Therefore, in this test, there was a remarkable difference between the strength correlation of 
concrete mixes made with W/B ratios of 0.4 and 0.55 .

- The measured compressive strength was different from the estimated compressive strength using Schmidt rebound hammer and PLT up to $7.9 \%$ and $38.1 \%$, respectively. However, the corresponding difference between the compression test and the strength estimated by the two-variable equation was $7.4 \%$ at the most. So, the reliability of the two-variable equation between PLI and rebound number was found to be more than that of one-variable equations to effectively determine the in-situ strength of the mixes including coarse natural concrete, recycled aggregate concrete, and PRAC under different curing regimes at early and old ages.

\section{Acknowledgment}

The authors gratefully acknowledge the Abadgaran Negin Jonoobshargh Company (A.N.J. Co.) for their support.

\section{References}

1. Madandoust R., Kazemi M. Numerical analysis of break-off test method on concrete. Construction and Building Materials, 2017;151:487-493.

2. Soares D., de Brito J., Ferreira J., Pacheco J. In situ materials characterization of fullscale recycled aggregates concrete structures. Construction and Building Materials, 2014;71:237-245.

3. Kazemi M., Madandoust R., de Brito J. Compressive strength assessment of recycled aggregate concrete using Schmidt rebound hammer and core testing. Construction and Building Materials, 2019;224:630-638.

4. Ferrara L. Citius, altius, fortius/faster, higher, tougher: pushing ahead the boundaries of structural concrete through fiber-reinforced cementitious composites with adapted rheology. Journal of Sustainable Cement-Based Materials, 2016;5(3):135-156.

5. Toufigh V., Jafarian Abyaneh M., Jafari K., Study of behavior of concrete under axial and triaxial compression, ACI Materials Journal, 2016; 114(04): 619-629.

6. Jahandari S., Toufigh M.M., Li J., Saberian M., Laboratory study of the effect of degrees of saturation on lime concrete resistance due to the groundwater level increment, Geotechnical and Geological Engineering, (2017a); 36(1): 413-424.

7. Bungey JH, Millard SG, Grantham MG. Testing of concrete in structures $\left(4^{\text {th }}\right.$ ed., p. 
352). London: Taylor \& Francis. 2006.

8. Robins PJ. Point load strength test for concrete cores. Magazine of Concrete Research, 1980;32(111):101-111.

9. Madandoust R, Bazkiyaei ZFZ, Kazemi M. Factor influencing point load tests on concrete. Asian Journal of Civil Engineering, 2018;19(8):937-947.

10. Ishibashi K, Zacoeb A, Ito Y. Influence of coarse aggregate size on the estimation of compressive strength of concrete by point load testing. Journal of Structures and Materials in Civil Engineering, 2008;24:108-115.

11. ACI 228.1R-03, In-place methods to estimate concrete strength, report by ACI committee 228. American Concrete Institute, 2003.

12. Kolek J. An appreciation of the Schmidt rebound hammer. Magazine of Concrete Research, 1958;10(28):27-36.

13. Grieb WE. Use of Swiss hammer for establishing the compressive strength of hardened concrete. Public Roads, 1958;201:1-14.

14. $\mathrm{Xu} \mathrm{T,} \mathrm{Li} \mathrm{J.} \mathrm{Assessing} \mathrm{the} \mathrm{spatial} \mathrm{variability} \mathrm{of} \mathrm{the} \mathrm{concrete} \mathrm{by} \mathrm{the} \mathrm{rebound} \mathrm{hammer} \mathrm{test}$ and compression test of drilled cores. Construction and Building Materials, 2018;188:820-832.

15. Taherkhani H. Evaluation of the physical properties of unbound base layer containing recycled aggregates. International Journal of Environmental Science and Development, 2015;6(4):279-285.

16. Saberian M, Li J, Nguyen BT, Setunge S. Estimating the resilient modulus of crushed recycled pavement materials containing crumb rubber using Clegg impact value, Resources. Conservation and Recycling, 2019;141:301-307.

17. Frondistou-Yannas S. Economics of concrete recycling in the United States. Adhesion Problems in the Recycling of Concrete, 1981;4:163-185.

18. Huda SB, Alam MS. Mechanical behavior of three generations of $100 \%$ repeated recycled coarse aggregate, concrete. Construction and Building Materials, 2014;65(4):574-582.

19. Li J, Saberian M, Nguyen BT. Effect of crumb rubber on the mechanical properties of crushed recycled pavement materials. Journal of Environmental Management, 2018;218:291-299.

20. de Brito J, Ferreira J, Pacheco J, Soares D, Guerreiro M. Structural, material, mechanical and durability properties and behaviour of recycled aggregates concrete. Journal of Building Engineering, 2016;6:1-16. 
21. Saberian M, Li J, Nguyen, BT, Boroujeni, M, Experimental and analytical study of dynamic properties of UGM materials containing waste rubber, Soil Dynamics and Earthquake Engineering, 2019; 130:1-12.

22. Santos S, da Silva PR, de Brito J. Self-compacting concrete with recycled aggregates-A literature review. Journal of Building Engineering, 2019;22:349-371.

23. Luo Z, Li W, Tam VWY, Xiao J, Shah SP. Current progress on nanotechnology application in recycled aggregate concrete. Journal of Sustainable Cement-Based Materials, 2019;8(2):79-96.

24. J.J. Assaad, P. Matar, A. Gergess Effect of quality of recycled aggregates on bond strength between concrete and embedded steel reinforcement. Journal of Sustainable CementBased Materials, 2019:1-18.

25. Madandoust R, Kazemi M, Moghadam SY. Analytical study on tensile strength of concrete. Romanian Journal of Materials, 2017;47(2):204-209.

26. Jahandari S, Li J, Saberian M, Shahsavarigoughari M. Experimental study of the effects of geogrids on elasticity modulus, brittleness, strength, and stress-strain behavior of lime stabilized kaolinitic clay. GeoResJ, 2017(a);13:49-58.

27. Matar P., Assaad J.J. Concurrent effects of recycled aggregates and polypropylene fibers on workability and key strength properties of self-consolidating concrete, Construction and Building Materials, 199 (2019) 492-500.

28. Das CS, Dey T, Dandapat R, Mukharjee BB, Kumar J. Performance evaluation of polypropylene fibre reinforced recycled aggregate concrete. Construction and Building Materials, 2018;189:649-659.

29. Madandoust R, Kazemi M, Khkapour Talebi P, de Brito J. Effect of the curing type on the mechanical properties of lightweight concrete with polypropylene and steel fibres. Construction and Building Materials, 2019;223:1038-1052.

30. Fallah S, Nematzadeh M. Mechanical properties and durability of high strength concrete containing macro-polymeric and polypropylene fibers with nano-silica and silica fume. Construction and Building Materials, 2017;132:170-187.

31. Jahandari S, Saberian M, Tao Z, Faridfazel Mojtahedi S, Li J, Ghasemi M, Rezvani SS, $\mathrm{Li}$ W. Effects of saturation degrees, freezing thawing, and curing on geotechnical properties of lime and lime-cement concretes. Cold Regions Science and Technology, 2019;160:242-251.

32. Jafari K., Tabatabaeian M., Joshaghani A., Ozbakkaloglu T. Optimizing the mixture design of polymer concrete: an experimental investigation. Construction and Building 
Materials, 2018; 167: 185-196.

33. AzariJafari H, Shekarchi M, Berenjian J, Ahmadi B. Enhancing workability retention of concrete containing natural zeolite by superplasticizers' combination. Special Publication, 2015;302:416-424.

34. Azarijafari H, Yahia A, Amor B. Removing shadows from consequential LCA through a time-dependent modeling approach: policy-making in the road pavement sector. Environmental Science \& Technology, 2019;53:1087-1097.

35. Ferreira L, de Brito J, Barra M. Influence of the pre-saturation of recycled coarse concrete aggregates on the fresh and hardened properties of concrete. Magazine of Concrete Research, 2011;63(8):617-627.

36. BS 1881: Part 202, Recommendations for surface hardness testing by rebound hammer. British Standards Institution, London, 1986.

37. ASTM C805, Rebound number of hardened concrete. American society for testing and materials, Philadelphia, 1985.

38. Gholhaki M, Kheyroddin A, Hajforoush M, Kazemi M. An investigation on the fresh and hardened properties of self-compacting concrete incorporating magnetic water with various pozzolanic materials. Construction and Building Materials, 2018;158:173-180.

39. Akça KR, Çakır Ö, Ipek M. Properties of polypropylene fiber reinforced concrete using recycled aggregates. Construction and Building Materials, 2015;98:620-630.

40. Behera M, Bhattacharyya SK, Minocha AK, Deoliya R, Maiti S. Recycled aggregate from $C \& D$ waste \& its use in concrete - a breakthrough towards sustainability in construction sector: a review. Construction and Building Materials, 2014;68:501-516. 


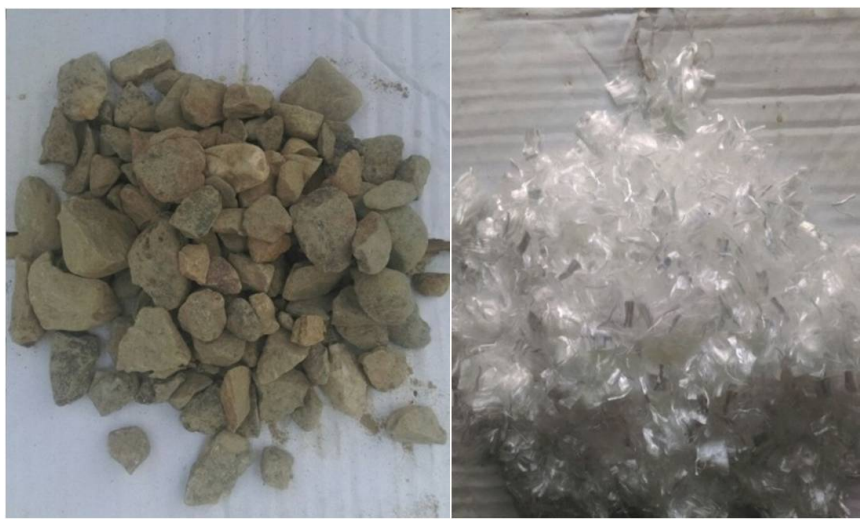

(a)

(b)

Fig. 1. Recycled coarse aggregate (a) polypropylene fibre (b). 


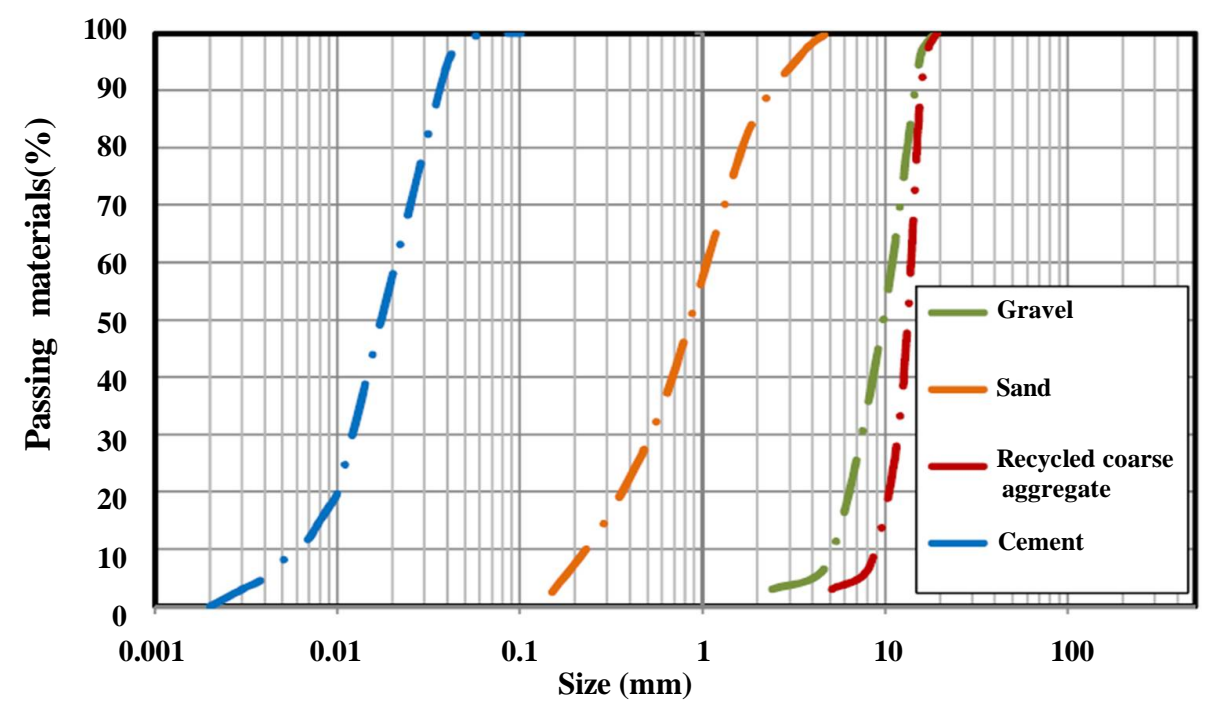

Fig. 2. The size distributions of the materials used in this study. 


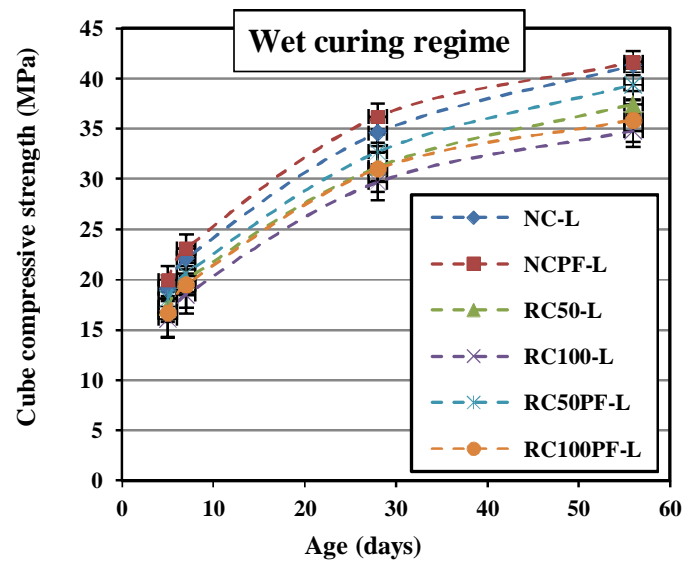

(a)

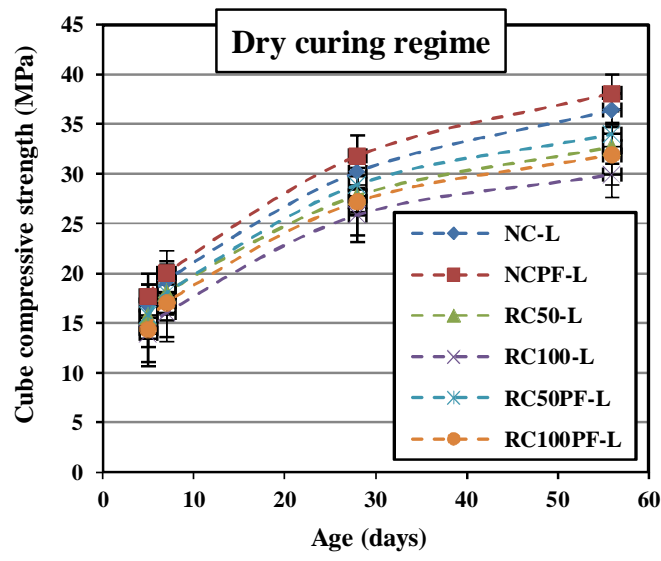

(b)

Fig. 3. Results of the compression test for mixes with W/B ratio of 0.4 under wet curing regime (a) and dry curing regime (b). 


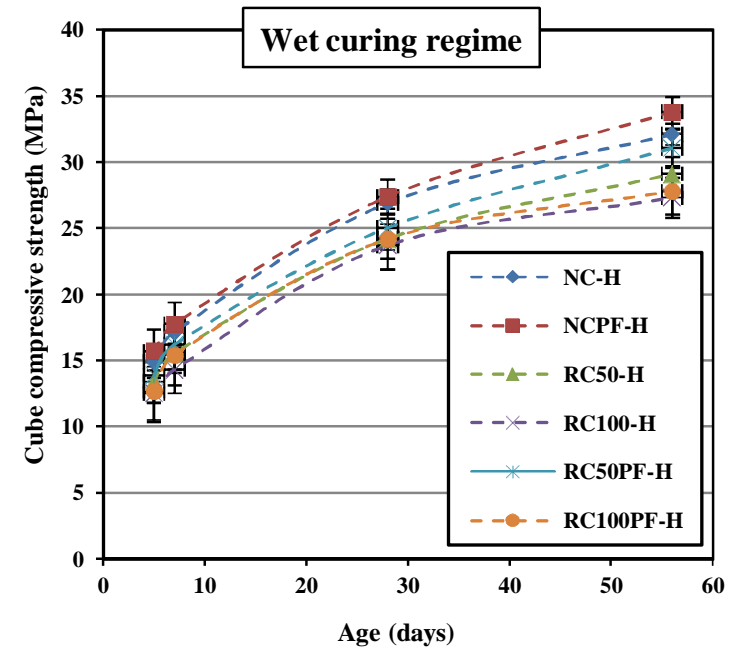

(a)

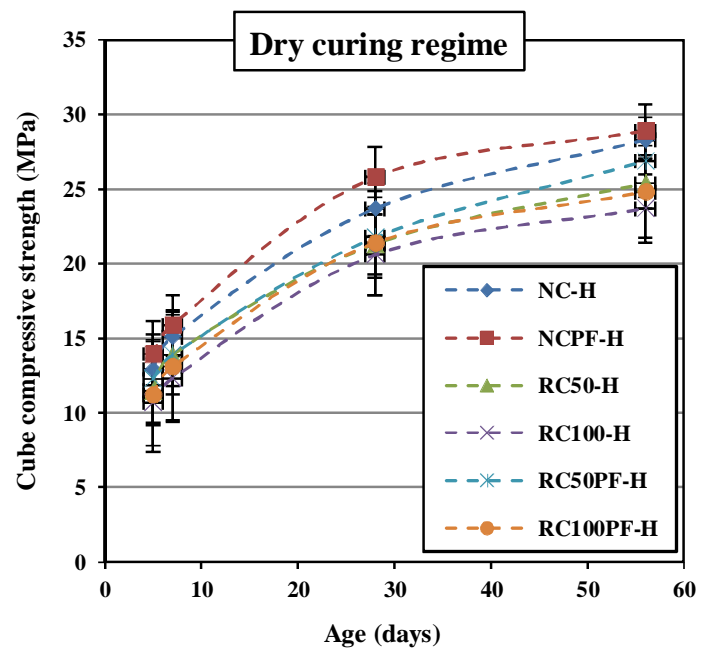

(b)

Fig. 4. Results of the compression test for mixes with W/B ratio of 0.55 under wet curing regime (a) and dry curing regime (b). 


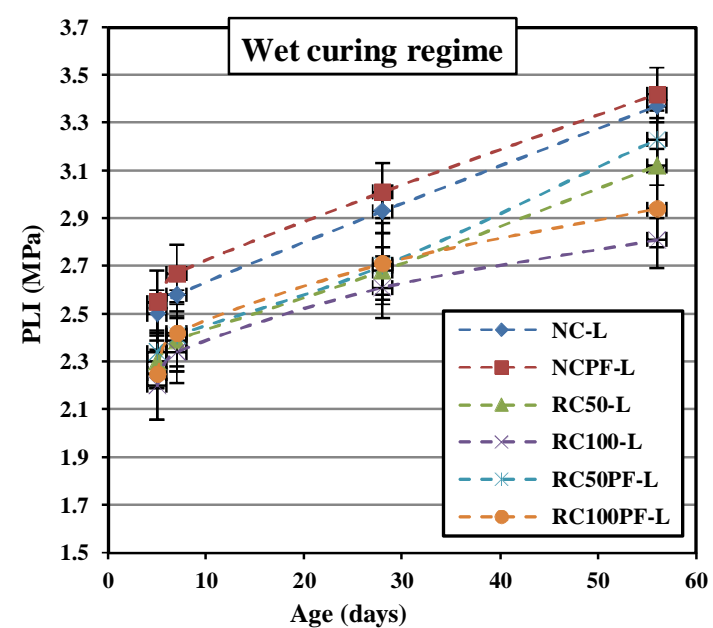

(a)

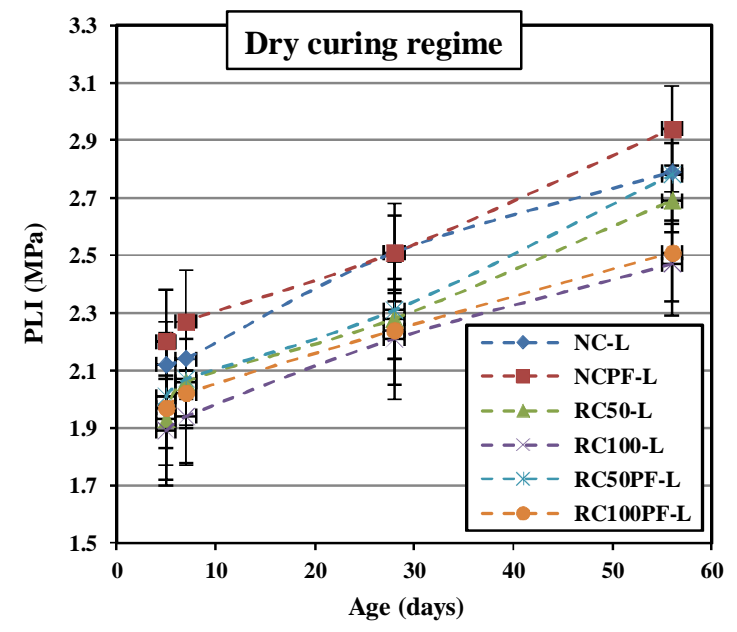

(b)

Fig. 5. PLI values of concrete specimens with W/B ratio of 0.4 under wet curing regime (a) and dry curing regime (b). 


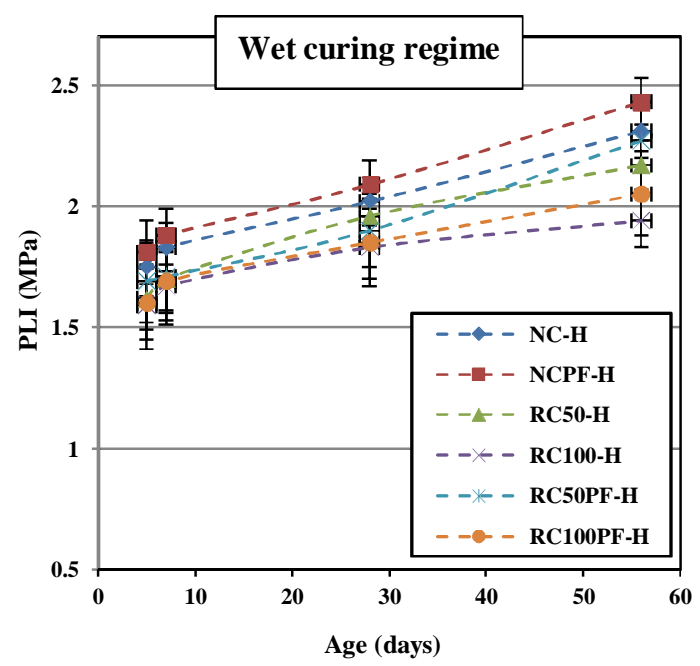

(a)

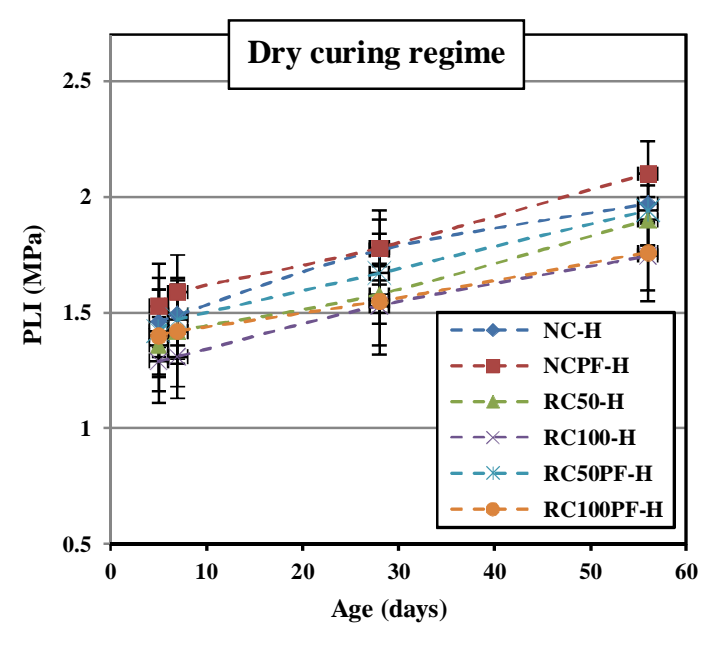

(b)

Fig. 6. PLI values of concrete specimens with W/B ratio of 0.55 under wet curing regime (a) and dry curing regime (b). 
Effect of PF on the postcracking behaviour of concrete

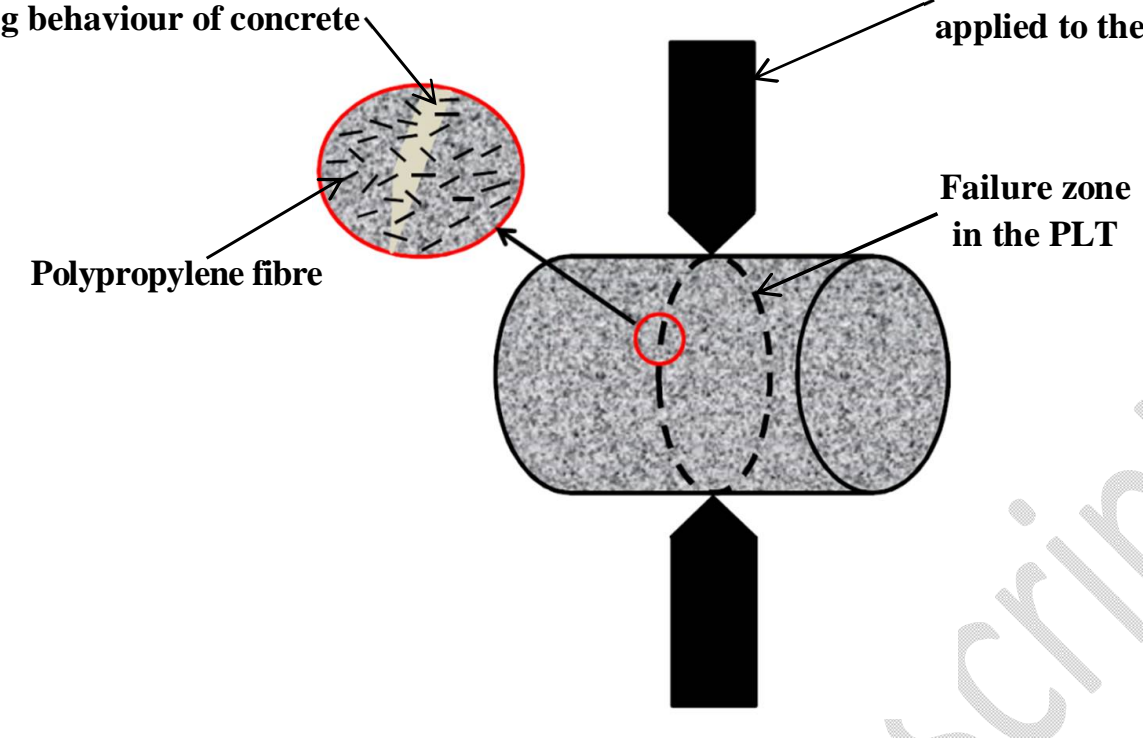

Fig. 7. Effect of PF content on the post-cracking behaviour of concrete in the PLT. 


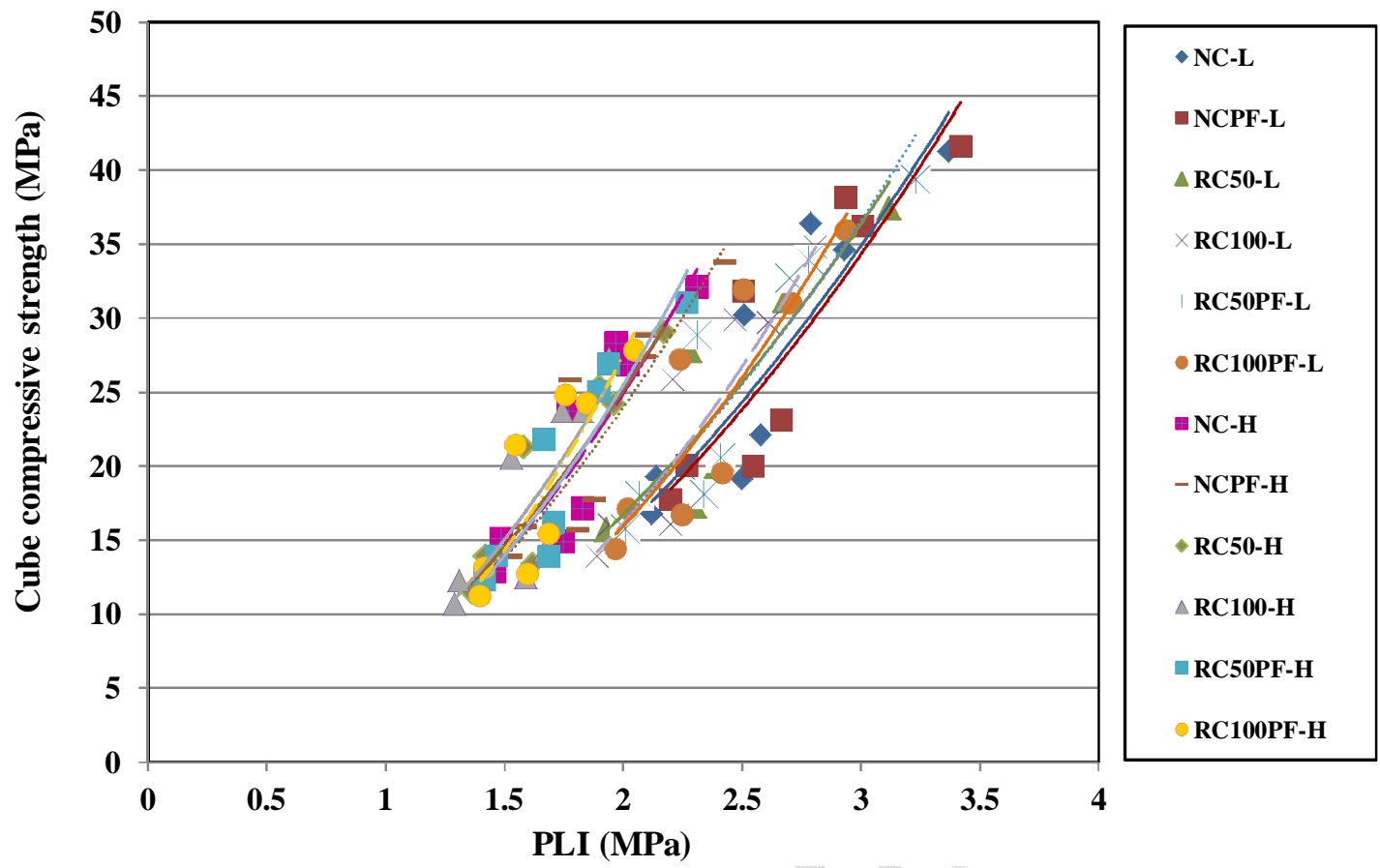

Fig. 8. Variation of cube compressive strength and PLI for recycled and natural aggregate concrete mixes made with and with no PF under different curing regimes. 


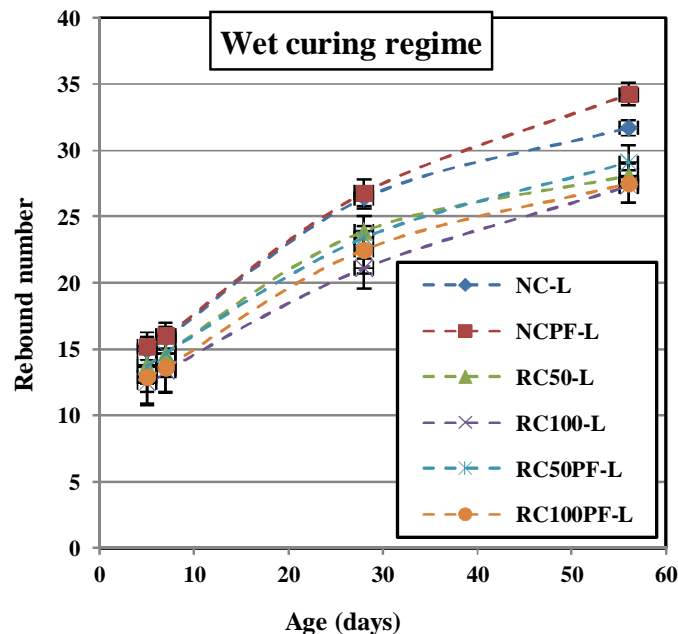

(a)

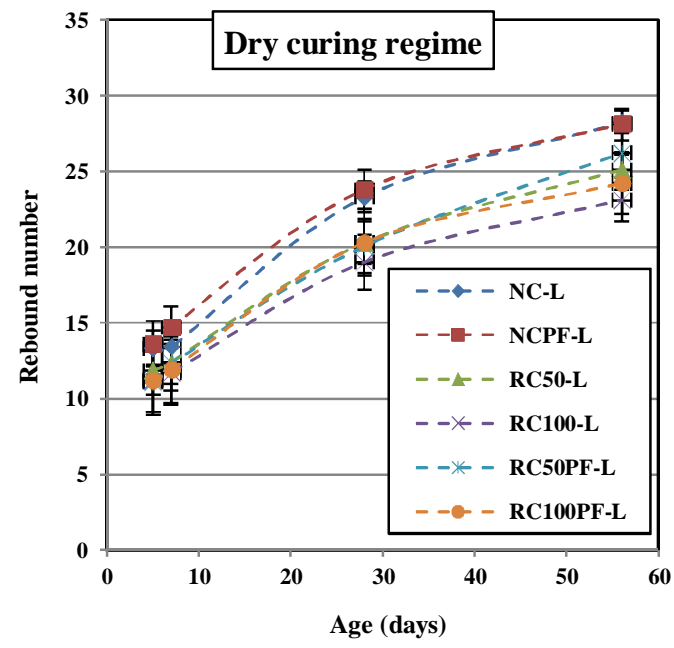

(b)

Fig. 9. Rebound numbers of mixes with W/B ratio of 0.4 under wet curing regime (a) and dry curing regime (b). 


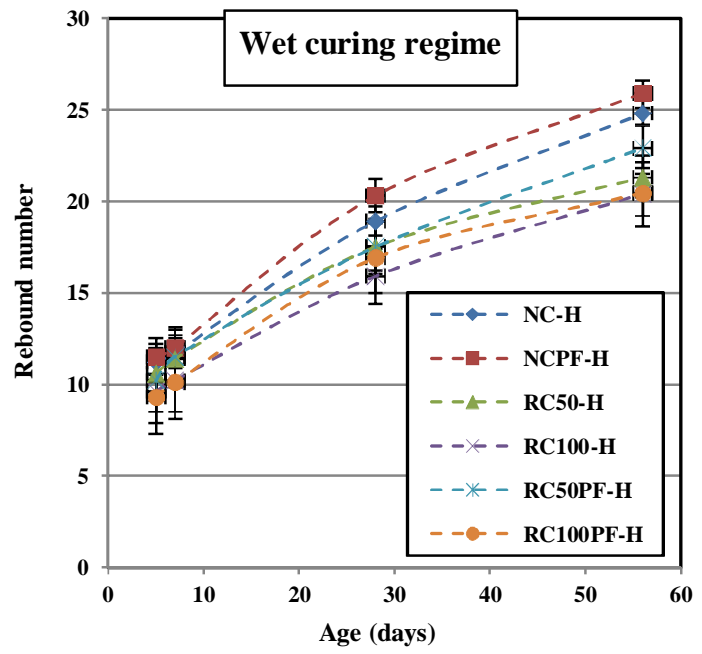

(a)

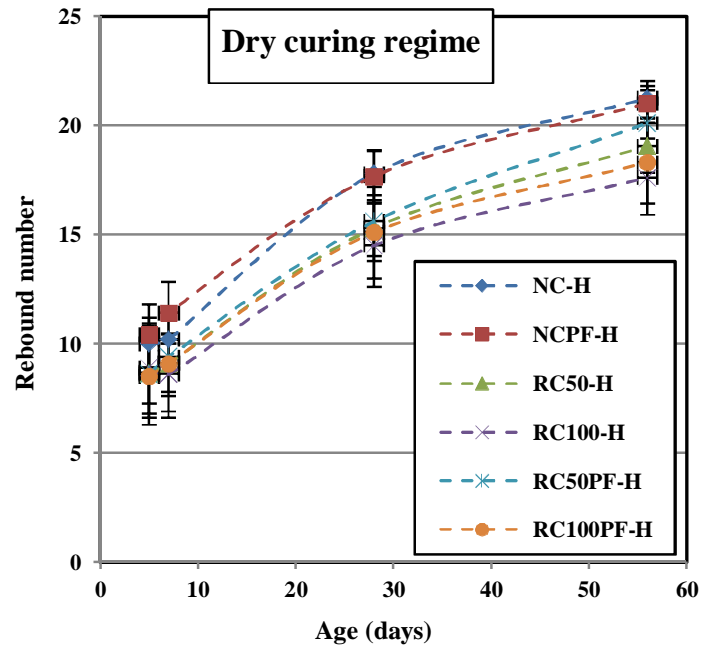

(b)

Fig. 10. Rebound numbers of mixes with W/B ratio of 0.55 under wet curing regime (a) and dry curing regime (b). 


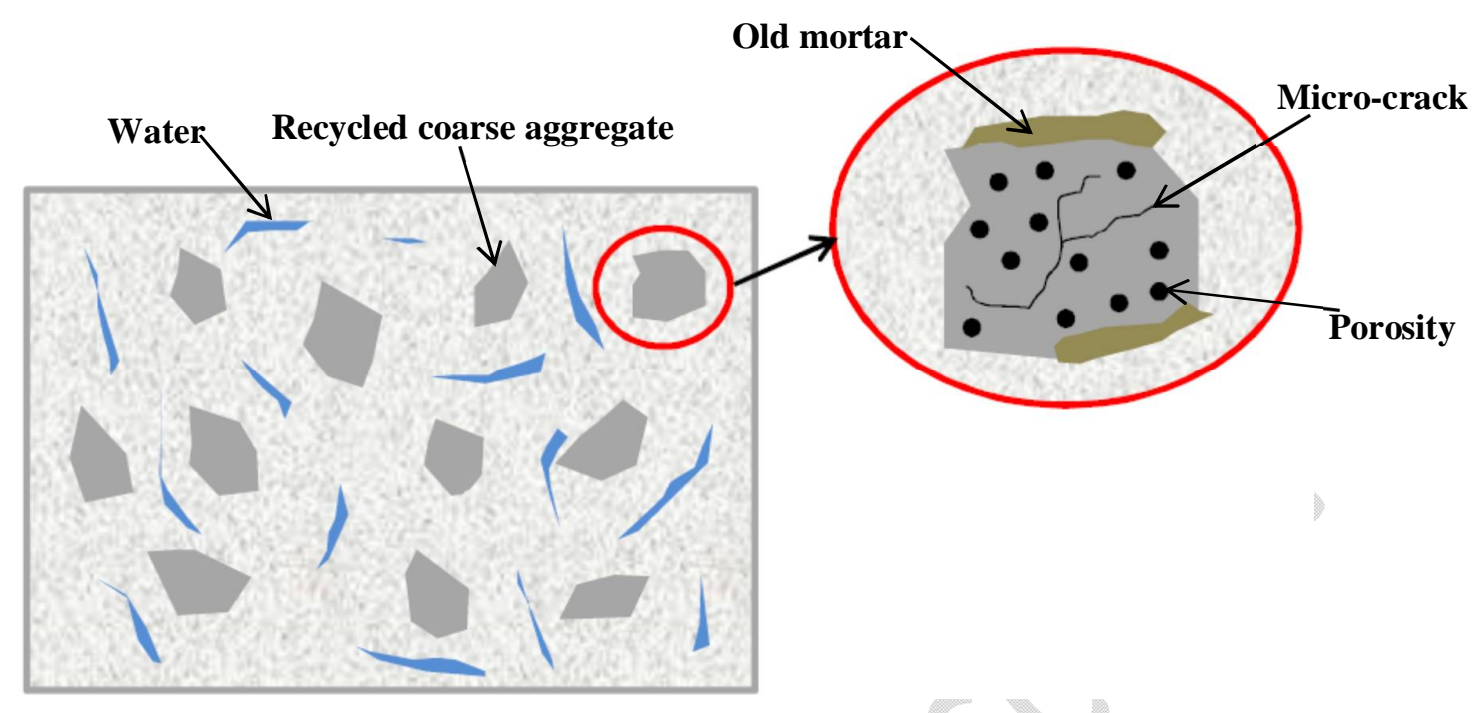

Fig. 11. Schematic representation of old mortar, micro-crack, and porosity in the surface of RAC. 


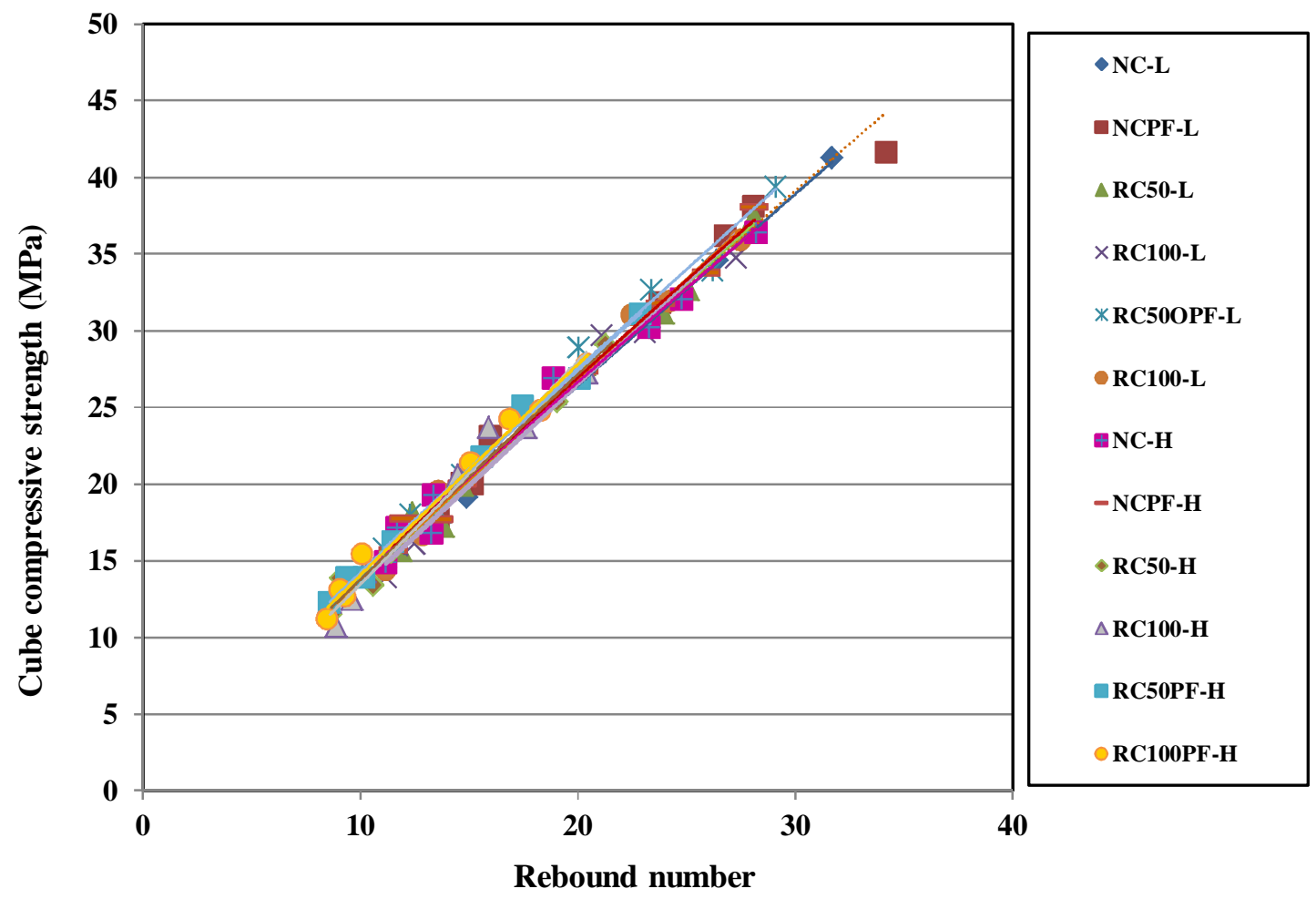

Fig. 12. Variation of cube compressive strength and rebound number for recycled and natural aggregate concrete mixes made with and with no PF under different curing regimes. 
Table 1. Chemical properties of cement.

\begin{tabular}{cc}
\hline Item & Cement (\%) \\
\hline $\mathrm{SIO}_{2}$ & 22.41 \\
$\mathrm{AL}_{2} \mathrm{O}_{3}$ & 4.55 \\
$\mathrm{Fe}_{2} \mathrm{O}_{3}$ & 3.9 \\
$\mathrm{CaO}$ & 64.3 \\
$\mathrm{MgO}$ & 0.9 \\
$\mathrm{SO}_{3}$ & 0.93 \\
$\mathrm{~K}_{2} \mathrm{O}$ & 0.54 \\
$\mathrm{C}_{3} \mathrm{~A}$ & 5.9 \\
$\mathrm{LOI}$ & 0.3
\end{tabular}


Table 2. Mix Designs.

\begin{tabular}{|c|c|c|c|c|c|c|c|}
\hline \multirow[b]{2}{*}{ Mix ID } & \multirow[b]{2}{*}{$\mathrm{PF}(\%)$} & \multirow[b]{2}{*}{$\begin{array}{l}\text { Cement } \\
\left(\mathrm{kg} / \mathrm{m}^{3}\right)\end{array}$} & \multirow[b]{2}{*}{$\mathrm{W} / \mathrm{B}$} & \multicolumn{2}{|c|}{ Gravel } & \multirow{2}{*}{$\begin{array}{c}\text { Sand } \\
\left(\mathrm{kg} / \mathrm{m}^{3}\right)\end{array}$} & \multirow{2}{*}{$\begin{array}{c}\text { Superplasticizer } \\
\qquad\left(\mathrm{kg} / \mathrm{m}^{3}\right)\end{array}$} \\
\hline & & & & $\begin{array}{l}\text { Natural } \\
\left(\mathrm{kg} / \mathrm{m}^{3}\right)\end{array}$ & $\begin{array}{c}\text { Recycled } \\
\left(\mathrm{kg} / \mathrm{m}^{3}\right)\end{array}$ & & \\
\hline $\mathrm{N}^{1} \mathrm{C}-\mathrm{L}^{2}$ & - & 440 & 0.4 & 988 & 0 & 691.6 & 0.8 \\
\hline NCPF-L & 0.1 & 440 & 0.4 & 988 & 0 & 691.6 & 0.8 \\
\hline $\mathrm{R}^{3} \mathrm{C} 50-\mathrm{L}$ & - & 440 & 0.4 & 494 & 494 & 691.6 & 0.8 \\
\hline RC100-L & 0.1 & 440 & 0.4 & 0 & 988 & 691.6 & 0.8 \\
\hline RC50PF-L & 0.1 & 440 & 0.4 & 494 & 494 & 691.6 & 0.8 \\
\hline RC100PF-L & 0.1 & 440 & 0.4 & 0 & 988 & 691.6 & 0.8 \\
\hline $\mathrm{NC}-\mathrm{H}^{4}$ & - & 440 & 0.55 & 988 & 0 & 691.6 & \\
\hline NCPF-H & 0.1 & 440 & 0.55 & 988 & 0 & 691.6 & \\
\hline RC50-H & - & 440 & 0.55 & 494 & 494 & 691.6 & \\
\hline $\mathrm{RC} 100-\mathrm{H}$ & 0.1 & 440 & 0.55 & 0 & 988 & 691.6 & - \\
\hline RC50PF-H & 0.1 & 440 & 0.55 & 494 & 494 & 691.6 & - \\
\hline RC100PF-H & 0.1 & 440 & 0.55 & 0 & 988 & 691.6 & - \\
\hline
\end{tabular}

\footnotetext{
${ }^{1}$ Natural aggregate

2 Low W/B ratio (0.4)

${ }^{3}$ Recycled aggregate

${ }^{4}$ High W/B ratio (0.55)
} 
Table 3. Slump values and the measured and estimated in-situ cube strengths.

\begin{tabular}{|c|c|c|c|c|c|c|}
\hline \multirow[b]{2}{*}{ No. } & \multirow[b]{2}{*}{ Mix ID } & \multirow{2}{*}{$\begin{array}{l}\text { Slump } \\
(\mathrm{mm})\end{array}$} & \multirow[t]{2}{*}{ Measured cube strength (MPa) } & \multicolumn{3}{|c|}{ Estimated cube strength } \\
\hline & & & & By PLT (MPa) & $\begin{array}{c}\text { Schmidt } \\
\text { hammer (MPa) }\end{array}$ & $\begin{array}{c}\text { By the two-variable } \\
\text { equation }(\mathrm{MPa})\end{array}$ \\
\hline 1 & NC-L (Wet) & 79 & 19.15 & $24.34(27.1 \%)$ & $19.9(3.9 \%)$ & $20.07(4.8 \%)$ \\
\hline 2 & NCPF-L (Wet) & 76 & 23.1 & $27.19(17.7 \%)$ & $21.7(6.5 \%)$ & $21.5(7.4 \%)$ \\
\hline 3 & RC50-L (Wet) & 73 & 31.2 & $29.3(6.5 \%)$ & $31.6(1.3 \%)$ & $31.7(1.6 \%)$ \\
\hline 4 & RC100-L (Dry) & 66 & 29.9 & $26(15 \%)$ & $30.7(2.7 \%)$ & $30.8(3 \%)$ \\
\hline 5 & RC50PF-L (Dry) & 72 & 15.8 & $16.6(5.1 \%)$ & $15.8(0 \%)$ & $15.3(3.3 \%)$ \\
\hline 6 & RC100PF-L (Dry) & 66 & 17.1 & $16.3(4.9 \%)$ & $16.2(5.6 \%)$ & $16.4(4.3 \%)$ \\
\hline 7 & NC-H (Wet) & 80 & 26.9 & $25.4(5.9 \%)$ & $25.3(6.4 \%)$ & $25.5(4.7 \%)$ \\
\hline 8 & NCPF-H (Wet) & 78 & 27.4 & $26.1(5 \%)$ & $27.3(0.4 \%)$ & $27.3(5.5 \%)$ \\
\hline 9 & RC50-H (Wet) & 75 & 29.1 & $29.3(0.7 \%)$ & $28.8(1 \%)$ & $28.6(1.8 \%)$ \\
\hline 10 & RC100-H (Dry) & 66 & 12.3 & $11.4(8.8 \%)$ & $11.4(7.9 \%)$ & $12.35(2.9 \%)$ \\
\hline 11 & RC50PF-H (Dry) & 74 & 21.75 & $17.5(24.3 \%)$ & $21.65(0.5 \%)$ & $21.3(2.1 \%)$ \\
\hline 12 & RC100PF-H (Dry) & 67 & 21.4 & $15.5(38.1 \%)$ & $21.1(1.4 \%)$ & $20.7(3.4 \%)$ \\
\hline
\end{tabular}


Table 4. The proposed one-variable equations.

\begin{tabular}{cccccc}
\hline \multirow{2}{*}{ No. } & \multirow{2}{*}{ Mix ID } & \multicolumn{2}{c}{ Relationship between cube } & \multicolumn{2}{c}{ Relationship between cube compressive } \\
\cline { 3 - 6 } & & \multicolumn{2}{c}{ compressive strength and PLI } & \multicolumn{2}{c}{ strength and rebound number } \\
\hline 1 & PC-L (Wet) & $\mathrm{f}_{\mathrm{c}}=3.9914 \mathrm{PLI}^{1.9735}$ & 0.79 & $\mathrm{f}_{\mathrm{c}}=1.5155 \mathrm{RN}^{0.9543}$ & 0.98 \\
2 & NCPF-L (Wet) & $\mathrm{f}_{\mathrm{c}}=3.8154 \mathrm{PLI}^{1.9995}$ & 0.78 & $\mathrm{f}_{\mathrm{c}}=1.5846 \mathrm{RN}^{0.9428}$ & 0.98 \\
3 & RC50-L (Wet) & $\mathrm{f}_{\mathrm{c}}=4.4457 \mathrm{PLI}^{1.9132}$ & 0.79 & $\mathrm{f}_{\mathrm{c}}=1.4777 \mathrm{RN}^{0.9653}$ & 0.98 \\
4 & RC100-L (Dry) & $\mathrm{f}_{\mathrm{c}}=3.3707 \mathrm{PLI}^{2.2598}$ & 0.79 & $\mathrm{f}_{\mathrm{c}}=1.314 \mathrm{RN}^{1.0034}$ & 0.98 \\
5 & RC50PF-L (Dry) & $\mathrm{f}_{\mathrm{c}}=4.1716 \mathrm{PLI}^{1.9769}$ & 0.8 & $\mathrm{f}_{\mathrm{c}}=1.6277 \mathrm{~N}^{0.9442}$ & 0.99 \\
6 & RC100PF-L (Dry) & $\mathrm{f}_{\mathrm{c}}=3.5003 \mathrm{PLI}^{2.1881}$ & 0.74 & $\mathrm{f}_{\mathrm{c}}=1.4532 \mathrm{RN}^{1.9734}$ & 0.98 \\
7 & NC-H (Wet) & $\mathrm{f}_{\mathrm{c}}=6.1772 \mathrm{PLI}^{2} .0121$ & 0.78 & $\mathrm{f}_{\mathrm{c}}=1.6646 \mathrm{RN}^{0.9258}$ & 0.97 \\
8 & NCPF-H (Wet) & $\mathrm{f}_{\mathrm{c}}=6.3135 \mathrm{PLI}^{1.9252}$ & 0.76 & $\mathrm{f}_{\mathrm{c}}=1.5737 \mathrm{RN}^{0.9482}$ & 0.99 \\
9 & RC50-H (Wet) & $\mathrm{f}_{\mathrm{c}}=6.7187 \mathrm{PLI}^{1.9029}$ & 0.78 & $\mathrm{f}_{\mathrm{c}}=1.4321 \mathrm{RN}^{0.9824}$ & 0.98 \\
10 & RC100-H (Dry) & $\mathrm{f}_{\mathrm{c}}=6.5212 \mathrm{PLI}^{2.0608}$ & 0.74 & $\mathrm{f}_{\mathrm{c}}=1.1818 \mathrm{RN}^{1.0566}$ & 0.97 \\
11 & RC50PF-H (Dry) & $\mathrm{f}_{\mathrm{c}}=5.9802 \mathrm{PLI}^{2.0912}$ & 0.82 & $\mathrm{f}_{\mathrm{c}}=1.6069 \mathrm{RN}^{0.9468}$ & 0.99 \\
12 & RC100PF-H (Dry) & $\mathrm{f}_{\mathrm{c}}=5.7032 \mathrm{PLI}^{2.27}$ & 0.72 & $\mathrm{f}_{\mathrm{c}}=1.4574 \mathrm{RN}^{0.9842}$ & 0.98 \\
\hline
\end{tabular}

